\title{
Completeness of Medication Reconciliation Performed by Pediatric Resident Physicians at Hospital Admission for Asthma
}

\author{
Ashley Martin, Jaime McDonald, and Joanna Holland
}

Can J Hosp Pharm. 2021;74(1):30-5

\begin{abstract}
Background: Medication errors at hospital admission, though preventable, continue to be common. The process of medication reconciliation has been identified as an important tool in reducing medication errors. The first step in medication reconciliation involves documenting a patient's best possible medication history (BPMH); at the authors' tertiary pediatric hospital, this step is completed at time of admission by resident physicians.
\end{abstract}

Objectives: To describe and quantify the completeness of admission BPMH by resident physicians for pediatric inpatients with asthma.

Methods: This single-centre, retrospective chart review evaluated documentation of admission medication reconciliation for pediatric inpatients with asthma who were admitted between January 2016 and December 2017. Medication reconciliation forms were deemed incomplete if records for asthma medications were missing drug name, inhaler strength or oral drug dose, directions for use, or evidence of reconciliation.

Results: A total of 241 charts were evaluated, of which 97 (40\%) had incomplete documentation for at least 1 medication; in particular, $48(37 \%)$ of the 130 inhaled corticosteroid orders were missing inhaler strength. For most of the charts with incomplete medication history (68\% [66/97]), no reason was documented; however, review of the medication reconciliation forms and physician notes revealed that families might have been unsure of a patient's home medications or physicians might have left it to the pharmacy to clarify medication doses.

Conclusions: Documentation of inhaler medications on admission medication reconciliation forms completed by resident physicians for pediatric patients with asthma was often incomplete. Future quality improvement interventions, including resident and patient education, are required at the study institution. Collaboration with pharmacy services is also likely to improve completeness of the medication reconciliation process.

Keywords: medication reconciliation, asthma, pediatrics

\section{RÉSUMÉ}

Contexte : Bien qu'elles soient évitables, les erreurs de médication au moment de l'admission à l'hôpital sont encore répandues. Le processus du bilan comparatif des médicaments a été reconnu comme étant un outil important pour réduire ces erreurs. La première étape du bilan comparatif des médicaments vise à décrire le meilleur schéma thérapeutique possible (MSTP) du patient; dans l'hôpital pédiatrique tertiaire des auteurs, les médecins résidents se chargent de cette étape au moment de l'admission.

Objectifs : Décrire et quantifier le degré d'exhaustivité du MSTP réalisé par les médecins résidents pour les patients en pédiatrie souffrant d'asthme.

Méthodes : Cet examen rétrospectif unicentrique des dossiers a permis d'évaluer l'élaboration du bilan comparatif des médicaments à l'admission en pédiatrie des patients souffrant d'asthme entre janvier 2016 et décembre 2017. Les formulaires de bilan comparatif des médicaments étaient jugés incomplets si les dossiers relatifs aux médicaments contre l'asthme n'indiquaient pas le nom du médicament, la force de l'inhalateur ou la dose orale du médicament, le mode d'emploi ou les preuves de conciliation médicamenteuse.

Résultats : L'évaluation portait sur 241 tableaux; au moins 1 médicament manquait dans la description de 97 d'entre eux (40\%); en particulier la force de l'inhalateur ne figurait pas dans 48 (37\%) des 130 ordonnances relatives aux corticostéroïdes administrés par inhalation. La plupart des tableaux dont I'histoire pharmacothérapeutique était incomplète (68 \% [66/97]) n'en indiquaient pas la raison; cependant, l'examen des formulaires du bilan comparatif des médicaments et les notes des médecins ont révélé que les familles n'étaient peut-être pas certaines des médicaments que le patient prenait à domicile ou que les médecins auraient pu laisser aux pharmaciens le soin de clarifier les doses.

Conclusions : La description des médicaments administrés au moyen d'inhalateurs au moment de l'admission, figurant sur les formulaires du bilan comparatif des médicaments remplis par les médecins résidents pour les patients en pédiatrie souffrant d'asthme, était souvent incomplète. De futures interventions sur l'amélioration de la qualité, y compris les instructions données au patient et au résident, sont nécessaires dans l'institution où s'est déroulée l'étude. II est probable que la collaboration avec les services de pharmacie améliorerait l'exhaustivité du processus du bilan comparatif des médicaments.

Mots-clés : bilan comparatif des médicaments, asthme, pédiatrie 


\section{INTRODUCTION}

Medication errors among pediatric patients upon admission to and discharge from hospital, though preventable, continue to be common. ${ }^{1}$ A systematic review evaluating the occurrence of medication discrepancies in the pediatric population found a high rate of discrepancies, ranging from $22 \%$ to $73 \%$ of patients, mostly related to admissions. ${ }^{2}$ Medication reconciliation identifies clinically significant discrepancies for nearly a quarter of the pediatric population. ${ }^{3}$ Given that asthma is the leading cause of hospital admission for children, ${ }^{4}$ incomplete or inaccurate reconciliation of asthma medications can lead to clinically significant medication errors in a large proportion of the pediatric inpatient population. Errors with asthma medications, including omission of inhaled corticosteroid during admission for asthma exacerbations, have the potential to increase length of stay and overall $\operatorname{costs}^{5}$; as such, appropriate medication reconciliation is imperative. However, specific data regarding the accuracy of medication reconciliation for pediatric patients with asthma are sparse.

Medication reconciliation was implemented in 2008 at our academic children's hospital in eastern Canada, which has 60 pediatric medical/surgical beds. Upon admission of any patient to the pediatric medical unit, the medication reconciliation process is initiated by resident physicians and is mandatory upon admission, transfer, and discharge. For each patient, a resident documents the best possible medication history (BPMH) using a preprinted order form. The form prompts the user to consult at least 2 sources, such as patient and family interviews, medical records, the provincial drug information system, or medication bottles. The listed medications are then assessed by the patient's health care team and a decision is made to continue, change, or discontinue the medications as indicated. This form, once signed by the physician, serves as the admission medication order. Typically, the form is then reassessed and reconciled by a pharmacist or a pharmacy technician upon receipt in the pharmacy. As part of their 2-year academic curriculum, resident physicians attend an educational session facilitated by a clinical pharmacist to learn about proper completion of the preprinted order form. Our literature review of medication reconciliation education initiatives targeted toward resident physicians found limited published data on the best way to approach this training. ${ }^{6-10}$

Medication reconciliation data for pediatric asthma are limited, as are data assessing the accuracy of medication reconciliation performed by medical residents, given that most studies to date have evaluated pharmacy-led initiatives. ${ }^{11}$ Therefore, this study aimed to assess the completeness of medication reconciliation forms prepared by resident physicians for pediatric inpatients with asthma. We performed a retrospective chart review to quantify and describe the medication discrepancies revealed through our medication reconciliation process and to inform future quality improvement initiatives. We hypothesized, on the basis of clinical observation and literature showing lower rates of accuracy among physicians, ${ }^{12}$ that the rate of discrepancies would be high, with the strength of asthma inhaler most frequently omitted on admission medication reconciliation.

\section{METHODS}

This study was a single-centre, retrospective chart review of admission documentation (specifically BPMH) for asthma medications completed by resident physicians as part of medication reconciliation. It was approved by the research ethics board at the study institution (project number 1023121). Inpatients with asthma, defined as patients with a primary or secondary admission diagnosis code for asthma who were admitted to intensive care or general medical units between January 2016 and December 2017, were included. A list of medical record numbers for the study period was provided by the health records department; for patients with multiple admissions during the study period, the preprinted order form for admission medication reconciliation for each individual admission was reviewed. The patient charts, which had been scanned to our hospital's clinical information system, were reviewed electronically by a single reviewer (A.M.).

A medication reconciliation form was deemed to be incomplete if records for asthma medications were missing a drug name, the inhaler strength or oral drug dose, directions for use, or evidence of reconciliation (i.e., decision to continue, hold, or discontinue the medication). For incomplete forms, the admission history and physical examination findings, physician progress notes, order sheets, and preliminary discharge summaries were reviewed to determine if the reason for the incomplete medication history had been documented. Patients with asthma who were not taking any medications at home were excluded from the review, and the completeness of documentation for non-asthma medications was not assessed. For the purpose of this review, failure to document strength of salbutamol metered-dose inhaler was not deemed to represent incomplete documentation, because only one strength of this medication is available in Canada.

Data were coded and entered into an Excel spreadsheet (Microsoft Corporation). Descriptive statistics were calculated for demographic data and were used to quantify the number of incomplete forms with missing information for different classes of asthma medications. In addition, descriptive statistics were used to categorize reasons for incomplete medication histories and whether medication orders were clarified before hospital discharge.

\section{RESULTS}

A total of 328 charts for pediatric inpatients with asthma admitted between January 2016 and December 2017 were 
identified. Of these, 241 charts had asthma medications listed on the admission form and were included for review. Short-acting bronchodilators constituted the most common class of medication, with 235 (98\%) of the charts mentioning this class as a home medication. The second most common medication class was inhaled corticosteroids (130 [54\%]). More than half (133 [55\%]) of the admission forms were completed by first-year medical residents, who provide on-call coverage for the inpatient medical unit at our centre more frequently than later-year residents. Other demographic data are presented in Table 1.

Overall, as outlined in Table 2, 97 (40\%) of the 241 forms reviewed had incomplete documentation for at least 1 medication, the most common reasons being missing inhaler strength/drug dose (33\% [143 of 437 individual medication orders]) or missing directions for use (19\% [84 of 437 individual medication orders). The most frequent class of medications with incomplete documentation was inhaled corticosteroids ( $n=130$ orders), with $40 \%$ incomplete for any reason, 37\% missing the inhaler strength, $14 \%$

\section{TABLE 1. Patient Characteristics}

\begin{tabular}{|c|c|c|}
\hline Characteristic & No. (\%) 0 & Patients ${ }^{\mathrm{a}}$ \\
\hline No. of charts reviewed & & \\
\hline Patient age (years) (median and IQR) & 4 & -17) \\
\hline Hospital admission year & & \\
\hline 2017 & 142 & (59) \\
\hline 2016 & 99 & (41) \\
\hline Home medications & & \\
\hline Short-acting bronchodilators & 235 & (98) \\
\hline Inhaled corticosteroids & 130 & (54) \\
\hline Montelukast & 34 & (14) \\
\hline Combination inhaler & 25 & (10) \\
\hline Oral corticosteroid & 13 & $(5)$ \\
\hline No. of home medications & & \\
\hline 1 or 2 & 156 & (65) \\
\hline $3-5$ & 71 & (29) \\
\hline$>5$ & 14 & (6) \\
\hline $\begin{array}{l}\text { Level of training of resident document } \\
\text { medication reconciliation }\end{array}$ & & \\
\hline Year 1 & 133 & (55) \\
\hline Year 2 & 33 & (14) \\
\hline Year 3 & 46 & (19) \\
\hline Year 4 & 23 & (10) \\
\hline Staff physician & 4 & (2) \\
\hline Not signed & 2 & (1) \\
\hline $\begin{array}{l}\text { Time when medication reconciliation } \\
\text { was completed }\end{array}$ & & \\
\hline Weekday day shift & 64 & (27) \\
\hline Weekday night shift & 116 & (48) \\
\hline Weekend shift & 61 & (25) \\
\hline
\end{tabular}

$\mathrm{IQR}=$ interquartile range. missing directions for use, $2 \%$ without reconciliation, and $1 \%$ missing the drug name. Overall, documentation was incomplete more often for inhaler medications than for oral medications: $27 \%(64 / 235)$ of forms for short-acting bronchodilators and $24 \%(6 / 25)$ of forms for combination inhalers were incomplete for any reason (Table 3).

The 97 charts with incomplete documentation of medication reconciliation were further reviewed to determine whether the prescriber acknowledged that the medication history was incomplete; for $19 \%$ (18/97), such acknowledgement appeared on the medication reconciliation form, and for $13 \%$ (13/97), it appeared in the history and physical or progress notes. The remaining 66 charts $(68 \%)$ had no documented reason for or acknowledgement of the incomplete orders. Reasons for missing information about patients' home medications as recorded in the charts included "patient/family unsure of dose", "parent does not have puffers", "clarify in the morning", and "pharmacy to clarify". Upon review of the 66 charts with incomplete medication reconciliation (excluding the 31 charts with only incomplete salbutamol documentation), 37 (56\%) were clarified by pharmacy before discharge, $5(8 \%)$ were clarified by the medical team before discharge, and 24 (36\%) were not clarified (Table 4).

\section{DISCUSSION}

Similar to results reported from other studies, ${ }^{2}$ information was missing for $40 \%$ of medication reconciliation forms completed by resident physicians for asthma admissions at our institution. As we anticipated, the information most commonly omitted was the strength of inhalers. In asthma management, where the controller medication is typically administered by inhaler, inaccurate documentation of home inhalers has the potential to cause medication errors, notably

TABLE 2. Frequency of Incomplete Medication

Reconciliation Forms and Missing Information

\begin{tabular}{lrr} 
Variable & $n / N(\%)$ \\
\hline No. of charts reviewed & 241 & \\
\hline No. of incomplete forms ${ }^{\mathrm{a}}$ & & \\
$\quad$ Overall & $97 / 241$ & $(40)$ \\
2017 & $51 / 142$ & $(36)$ \\
2016 & $46 / 99$ & $(46)$ \\
\hline Asthma medication orders (all charts) & 437 & \\
Charts with missing information & & \\
$\quad$ Missing drug name & $2 / 437$ & $(<1)$ \\
$\quad$ Missing inhaler strength or drug dose & $143 / 437$ & $(33)$ \\
Missing directions for use & $84 / 437$ & $(19)$ \\
Not reconciled & $11 / 437$ & $(3)$ \\
\hline
\end{tabular}

a If the only information missing was strength for salbutamol by metereddose inhaler, the form was deemed to be complete. 
TABLE 3. Completeness of Medication Reconciliation Documentation at Time of Admission, by Asthma Medication Class

\begin{tabular}{|c|c|c|}
\hline Variable & $\begin{array}{r}\text { No. ( } \\
\text { Incom }\end{array}$ & $\begin{array}{l}\text { Orders } \\
\text { by Class }\end{array}$ \\
\hline Inhaled corticosteroid & \multicolumn{2}{|c|}{$n=130$} \\
\hline Total incomplete & 52 & $(40)$ \\
\hline Missing drug name & 1 & (1) \\
\hline Missing inhaler strength & 48 & (37) \\
\hline Missing directions for use & 18 & (14) \\
\hline Not reconciled & 3 & $(2)$ \\
\hline Short-acting bronchodilators & \multicolumn{2}{|c|}{$n=235$} \\
\hline Total incomplete & 64 & $(27)$ \\
\hline Missing drug name & 1 & $(<1)$ \\
\hline Missing inhaler strengtha & 87 & (37) \\
\hline Missing directions for use & 59 & $(25)$ \\
\hline Not reconciled & 8 & (3) \\
\hline Montelukast & \multicolumn{2}{|c|}{$n=34$} \\
\hline Total incomplete & 4 & $(12)$ \\
\hline Missing drug name & 0 & (0) \\
\hline Missing drug dose & 3 & (9) \\
\hline Missing directions for use & 4 & $(12)$ \\
\hline Not reconciled & 0 & $(0)$ \\
\hline Combination inhaler & \multicolumn{2}{|c|}{$n=25$} \\
\hline Total incomplete & 6 & $(24)$ \\
\hline Missing drug name & 0 & $(0)$ \\
\hline Missing inhaler strength & 5 & $(20)$ \\
\hline Missing directions for use & 2 & $(8)$ \\
\hline Not reconciled & 0 & $(0)$ \\
\hline Oral steroid & \multicolumn{2}{|c|}{$n=13$} \\
\hline Total incomplete & 1 & (8) \\
\hline Missing drug name & 0 & (0) \\
\hline Missing drug dose & 0 & $(0)$ \\
\hline Missing directions for use & 1 & (8) \\
\hline Not reconciled & 0 & $(0)$ \\
\hline
\end{tabular}

alf the only information missing was strength for salbutamol by metereddose inhaler, the form was deemed to be complete (i.e., not counted in the "total incomplete" for this class).

delayed treatment if a nurse is unable to administer the medication until the incomplete order has been clarified. Of note, salbutamol documentation was rarely clarified because most patients with acute asthma exacerbation are transitioned to a preprinted order set, with appropriate weight-based salbutamol dosing. However, any delay or omission of inhaled corticosteroids has implications for quality of care and patient safety; for example, prospective data from a double-blind, randomized controlled trial showed that children continuing with inhaled corticosteroid therapy during hospital admission for acute asthma exacerbation may have shorter lengths of stay, with reduced overall costs, than children who do not continue with their home therapy while in hospital. ${ }^{5}$ For the large number of orders that remain unclarified at discharge, adverse outcomes (including loss of symptom control or
TABLE 4. Reasons for Incomplete Documentation of Medication Reconciliation and Predischarge Clarification

\begin{tabular}{lcc} 
Variable & \multicolumn{3}{c}{ No. (\%) } \\
\hline Reason for incomplete documentation & $n=97$ & incomplete orders \\
None documented & 66 & $(68)$ \\
Acknowledged incomplete on & 18 & $(19)$ \\
$\quad$ medication reconciliation form & & \\
Acknowledged incomplete on historyl & 13 & $(13)$ \\
$\quad$ physical findings or progress note & & \\
Clarification of medication orders & $n=66$ orders with no \\
before discharge ${ }^{\mathrm{a}}$ & \multicolumn{3}{c}{ reason documented } \\
By medical team & \multicolumn{3}{c}{5} & $(8)$ \\
By pharmacy & 37 & $(56)$ \\
Not clarified & 24 & $(36)$ \\
\hline
\end{tabular}

${ }^{a}$ Excluding incomplete salbutamol documentation.

unnecessary risk of adverse effects) may occur if the patient is unintentionally discharged on an incorrect dose of inhaled corticosteroid. Information about home dosing is frequently used by clinical staff to determine the need for escalation of therapy or to assess potential nonadherence as the reason for admission.

In the majority of charts with incomplete medication reconciliation, the reason was not documented. However, previous studies have noted various barriers to documentation, including unreliable sources of medication information and perceived higher-priority tasks that compete for providers' time and attention. ${ }^{13}$ Where residents did provide a reason for incomplete medication reconciliation, they most commonly mentioned that patients and families did not know the name or strength of their medications. In multiple admission histories, inhalers were documented by colour, such as "orange and blue puffers", when families were unsure of the product name or strength. These results are concerning, given that published data show poorer symptom control and medication adherence among children of parents who are unable to name their children's asthma inhalers. ${ }^{14}$ In our region, physicians can access a provincial drug information system that provides an electronic record of prescriptions dispensed to individual patients. However, according to anecdotal information, physician awareness and use of this system are minimal at our institution. Although use of the drug information system was not formally recorded as part of this study, it was infrequently marked as a source of information on medication reconciliation forms completed by residents. Alternatively, incomplete medication documentation could represent a gap in knowledge among trainees that multiple strengths of inhalers are available.

At our institution, pharmacy was responsible for the majority of predischarge clarifications. However, $36 \%$ of incomplete medication reconciliation forms remained unclarified at discharge; many of these discharges occurred on the weekend, when clinical pharmacy services are not 
available on the medical ward. Although increasing physicians' competency to perform medication reconciliation is a reasonable solution, most studies have noted little effect of medication reconciliation education directed at medical residents. ${ }^{6}$ Given the aforementioned limitation of physicians favouring tasks of higher priority, delegation of medication reconciliation to an alternative health care provider may be a more worthwhile intervention. Studies have shown that pharmacist-acquired medication histories are more accurate than physician-acquired histories ${ }^{12,15}$ and that pharmacy technicians are at least as accurate as pharmacists in performing this task, at a fraction of the cost. ${ }^{16}$ In one study, transferring responsibility for medication reconciliation from medical residents to pharmacy technicians (under pharmacist supervision) was effective and well received by resident and staff physicians as well as by pharmacy technicians. ${ }^{17}$ Therefore, developing a program for pharmacy technician-led medication reconciliation may represent the most reasonable approach to addressing the issues identified in the current study.

Our study had a number of limitations. First, we looked only at the completeness of admission medication reconciliation documentation and not the accuracy. We therefore were unable to quantify medication histories with incorrect doses or frequencies and did not capture whether home medications were omitted or ordered unintentionally. Second, it is possible that we overestimated the number of discrepancies that remained unclarified at discharge, because some may have been clarified verbally and correctly recorded on discharge prescriptions. Third, this chart review was completed by a single reviewer; although the outcomes themselves were not subjective, this might have been a source of bias.

The problem of poor documentation of asthma medication history is unlikely to be unique to our institution, and future quality improvement interventions are required. Studies conducted in other centres might yield different findings, especially if they have computerized physician order entry and forcing functions that require dose and frequency to be included for all medication orders. Although educational interventions have been of limited effectiveness, ${ }^{6}$ certain individual centres have had success in reducing medication discrepancies by increasing the education of medical residents. ${ }^{7,8,18}$ At our institution, increasing resident education to include the full and ongoing process of medication reconciliation, rather than just the technical aspects of completing a BPMH on a preprinted order form, may be of benefit. Mandating access to provincial electronic drug information systems for prescribers, as well as partnering with clinical pharmacists and pharmacy technicians at the time of admission, to facilitate communication with patients' community pharmacies, would result in more complete medication histories. In addition, patients and families must be educated about the importance of bringing an accurate medication list when accessing health care.

\section{CONCLUSION}

Documentation of inhaler medications on admission medication reconciliation forms prepared by resident physicians for pediatric asthma patients was often incomplete. Missing information about home asthma medications could negatively affect patient care and has potential to result in medication errors, adverse events, increased length of stay, and increased costs.

Future quality improvement interventions directed at the medication reconciliation process are required at the study institution, including increasing prescriber education and encouraging prescribers to access the provincial drug information system. Pharmacy services and resources, notably pharmacy technicians, have an important role to play in developing targeted solutions for this patient safety issue.

\section{References}

1. Huynh C, Tomlin S, Jani Y, Solanki GA, Haley H, Smith RE, et al. An evaluation of the epidemiology of medication discrepancies and clinical significance of medicines reconciliation in children admitted to hospital. Arch Dis Child. 2016;101(1):67-71.

2. Huynh C, Wong IC, Tomlin S, Terry D, Sinclair A, Wilson K, et al. Medication discrepancies at transitions in pediatrics: a review of the literature. Paediatr Drugs. 2013;15(3):203-15.

3. Coffey M, Mack L, Streitenberger K, Bishara T, De Faveri L, Matlow A. Prevalence and clinical significance of medication discrepancies at pediatric hospital admission. Acad Pediatr. 2009;9(5):360-5.

4. Ortiz-Alvarez O, Mikrogianakis A; Canadian Paediatric Society, Acute Care Committee. Managing the paediatric patient with an acute asthma exacerbation. Paediatr Child Health. 2012;17(5):251-5.

5. Razi CH, Akelma AZ, Harmanci K, Kocak M, Can YK. The addition of inhaled budesonide to standard therapy shortens the length of stay in hospital for asthmatic preschool children: a randomized, double-blind placebo-controlled trial. Int Arch Allergy Immunol. 2015;166(4):297-303.

6. Ramjaun A, Sudarshan M, Patakfalvi L, Tamblyn R, Meguerditchian AN. Educating medical trainees on medication reconciliation: a systematic review. BMC Med Educ. 2015;15(1):33.

7. Almidani E, Khadawardi E, Alshareef T, Hussain IB, Almofada S, Ham AJ, et al. Improving medication reconciliation compliance at admission: a single department's experience. Int J Pediatr Adolesc Med. 2015; 2(3-4):141-6

8. Arundel C, Logan J, Ayana R, Gannuscio J, Kerns J, Swenson R. Safe medication reconciliation: an intervention to improve residents' medication reconciliation skills. J Grad Med Educ. 2015;7(3):407-11.

9. Varkey P, Cunningham J, O’Meara J, Bonacci R, Desai N, Sheeler R. Multidisciplinary approach to inpatient medication reconciliation in an academic setting. Am J Health Syst Pharm. 2007;64(8):850-4

10. Chan AHY, Garratt E, Lawrence B, Turnbull N, Pratapsingh P, Black PN. Effect of education on the recording of medicines on admission to hospital. J Gen Intern Med. 2010;25(6):537-42.

11. Kwan JL, Lo L, Sampson M, Shojania KG. Medication reconciliation during transitions of care as a patient safety strategy: a systematic review. Ann Intern Med. 2013;158(5 Pt 2):397-403.

12. De Winter S, Spriet I, Indevuyst C, Vanbrabant P, Desruelles D, Sabbe $\mathrm{M}$, et al. Pharmacist-versus physician-acquired medication history: a prospective study at the emergency department. BMJ Qual Saf. 2010; 19(5):371-5.

13. Boockvar KS, Santos SL, Kushniruk A, Johnson C, Nebeker JR. Medication reconciliation: barriers and facilitators from the perspectives of resident physicians and pharmacists. J Hosp Med. 2011;6(6):329-37.

14. Frey SM, Fagnano M, Halterman J. Medication identification among caregivers of urban children with asthma. Acad Pediatr. 2016;16(8): 799-805. 
15. Reeder TA, Mutnick A. Pharmacist-versus physician-obtained medication histories. Am J Health Syst Pharm. 2008;65(9):857-60.

16. Johnston R, Saulnier L, Gould O. Best possible medication history in the emergency department: comparing pharmacy technicians and pharmacists. Can J Hosp Pharm. 2010;63(5):359-65.

17. Sen S, Siemianowski L, Murphy M, Mcallister SC. Implementation of a pharmacy technician-centered medication reconciliation program at an urban teaching medical center. Am J Health Syst Pharm. 2014;71(1):51-6.

18. Sedgh S, Kantrowitz M, Shamah S, Agarwal A, Fernandez V, Cohen D. Q-Tip: resident-driven quality improvement to inpatient medication reconciliation in an academic setting. Am J Med Qual. 2013;28(4):357.
Ashley Martin, MD, FRCPC, is a Pediatric Emergency Medicine Resident at Dalhousie University, Halifax, Nova Scotia.

Jaime McDonald, PharmD, is a Pharmacist with the IWK Health Centre, Halifax, Nova Scotia.

Joanna Holland, MD, FRCPC, is Assistant Professor in the Department of Pediatrics, Dalhousie University, Halifax, Nova Scotia.

Competing interests: For activities outside the study reported here, Jaime McDonald has received grants from MedBuy and the Academic Health Science Centre Alternate Funding Plan Innovation Fund and is a participating author for an unrelated study that will use drug products manufactured by AA Pharmac Inc, Apotex Inc, Pharmascience Inc, OMEGA Laboratories Ltd, and Teva Canada Inc. No other competing interests were declared.

\section{Address correspondence to:}

Dr Ashley Martin

IWK Health Centre

5850/5980 University Avenue, PO Box 9700

Halifax NS B3K 6 R8

email: Ashley.Martin@dal.ca

Funding: None received.

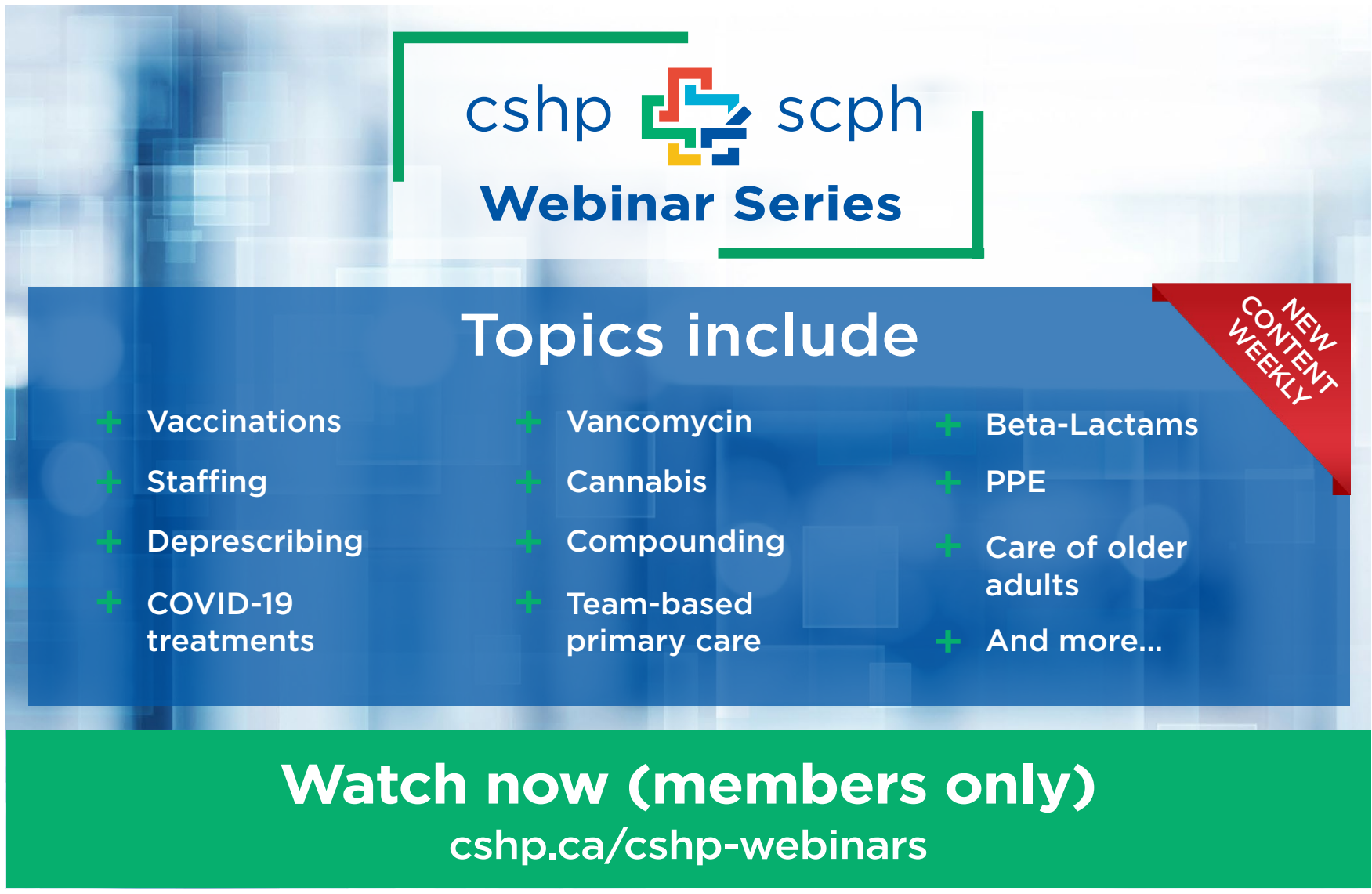

